\title{
RESEARCH
}

\section{Sex differences in the effectiveness of statins after myocardial infarction}

\section{Igor Karp, Shun-Fu Chen, Louise Pilote}

\section{ABSTRACT}

Background: We sought to investigate the sex differences in the effectiveness of statins in patients with acute myocardial infarction (AMI).

Methods: Linking hospital discharge and drug claims databases from Quebec, Canada (1998-2004), we identified statin users $(n=14710)$ and non-users $(n=23$ 833) discharged from hospital after an AMI-related hospital stay and followed up for as long as 7 years.

Results: All-cause death rates were 4.1 and 14.6 per 100 person-years among users and non-users, respectively, whereas cardiac death rates were 2.2 and 7.4 per 100 person-years. For death from any cause, the adjusted hazard ratios associated with statin use in women were 0.61 (95\% confidence interval $[\mathrm{Cl}], 0.54-0.69)$ within 1 year of followup, $0.55(0.48-0.63)$ at $1-3$ years and $0.38(0.31-0.49)$ at $>3$ years; in men, the corresponding estimates were $0.54(0.48$ $0.60), 0.48(0.42-0.55)$ and $0.34(0.30-0.39)$. For cardiacrelated death, the adjusted hazard ratios associated with statin use in women were $0.70(0.60-0.81)$ within 1 year, 0.56 $(0.46-0.68)$ at $1-3$ years and $0.44(0.31-0.62)$ at $>3$ years of follow-up, whereas in men, the estimates were 0.59 (0.51$0.69), 0.47\left(0.39-0.5^{8}\right)$ and 0.37 (0.30-0.45), respectively.

Interpretation: Statin therapy after an AMI was associated with reduced rates of all-cause and cardiac mortality. The effect increased with time in both sexes, but the degree of risk reduction was less for women than for men.

CMAJ 2007;176(3):333-8

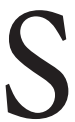

tatins have been shown to be effective medications for prevention of secondary events in patients with coronary heart disease (CHD). ${ }^{1-3}$ However, because women have been underrepresented in clinical trials on statins, ${ }^{4}$ potential sex differences in the efficacy of statins have not been well studied. Among the studies that explored this issue, some indicated a possibly greater cardiovascular risk reduction among men, ${ }^{5,6}$ whereas others suggested that statins were as effective in women as in men, or even more effective..$^{7-10}$ This latter proposition would indeed be consistent with the greater low-density lipoprotein (LDL) cholesterol and total cholesterol reductions in women than in men in response to the use of statins that were reported from some earlier studies. ${ }^{11-13}$
Current knowledge about the magnitude of the statininduced risk reduction in death rates among women with CHD or cardiovascular disease (CVD) in general is even less definitive. Whereas at least 2 studies have reported a potential benefit of statins in women, ${ }^{14,15}$ a recent systematic review ${ }^{16}$ concluded that lipid-lowering medications, including statins, did not reduce total mortality rates among women with CVD, just as they did not among women without CVD. However, the review did find statistically significant reductions in CHDrelated deaths, nonfatal myocardial infarction, revascularization and total CHD events accompanying lipid-lowering therapy in women with CVD. ${ }^{16}$

Thus, the current evidence on potential quantitative differences in the efficacy of statins for prevention of secondary events in men and women with CHD is still inconclusive. We conducted this study to investigate possible statistical sexstatin interaction in patients after a myocardial infarction (AMI).

\section{Methods}

The Quebec hospital discharge summary database, which includes information on all hospital admissions for AMI, was linked to provincial databases of physician and drug claims. In Quebec, people younger than 65 years typically receive drug benefits through employee plans; those without employee benefits or who are aged 65 years and over receive prescription coverage at minimal cost. Thus, our source of drug data included information on patients of all ages. For completeness, vital status information was obtained from the same databases, which are linked to pension, car insurance and death registry services. The patients' unique, encrypted health care insurance number was used to link the data within and between the databases. During the linkage, a total of 53 subjects could not be matched and were therefore excluded from our analyses.

Patients with a first record of an AMI-related hospital admission who were discharged alive between April I, I998 and March 3I, 2004 were included in the cohort. (The interval was based on the most recently available data from the hospital discharge database.) All patients had AMI (ICD-9-CM code $4 \mathrm{IO})^{17}$ recorded in the hospital discharge database as the most responsible diagnosis - that is, the principal diagnosis contributing to the greatest extent to the patient's hospital stay.

Patients were excluded (for the reason in parentheses) if they met any of the following criteria: the AMI was coded as 
an in-hospital complication (to minimize the possibility of including iatrogenic AMI cases); the AMI-related hospital admission was a transfer from another hospital (to avoid counting the patients more than once); the total length of hospital stay was less than 2 days (to exclude patients with ruled-out AMI cases and those admitted only for procedures); the patient was discharged to a long-term care institution or rehabilitation centre, or moved out of the province (since data on prescriptions would then be unavailable); or the health care number was invalid. More details of the rationale for these criteria can be found elsewhere. ${ }^{18}$

Statin use was defined as data indicating a prescription filled for any of the 6 statin medications, which are considered to be of similar effectiveness for the prevention of secondary events in patients with CHD: atorvastatin, pravastatin, simvastatin, lovastatin, rosuvastatin and fluvastatin. ${ }^{19}$ Available prescription information (type of drug, dosage category, frequency and duration) was used to calculate daily dosages, which were converted into equivalent atorvastin doses and the corresponding number of Defined Daily Doses (DDD), as defined by the World Health Organization. ${ }^{20}$ Based on the patient's statin-prescription status at the time of discharge (time zero), 2 study groups were retrospectively defined: patients who were prescribed a statin (statin users) and those not prescribed a statin (statin non-users, the control group). Each patient was followed from time zero until the occurrence of either of the study end-points (all-cause death and cardiac death [ICD-9-CM codes 390-450, 785 or v588]), ${ }^{17}$ the end of study follow-up (March 3I, 2005), loss to follow-up, or discontinuation of the statin use/non-use regimen initially adopted, whichever came first. In the last case, statin users were considered to have discontinued statin use if at least 30 consecutive days passed during which they did not fill a prescription for a statin. Among statin users, switching the type of statin used (i.e., among the 6 statin medications) would not represent a discontinuation. On the other hand, switching from a statin medication to a nonstatin drug or to a statin other than the 6 types already mentioned would represent a statin discontinuation for the purposes of our study.

Potential confounders were taken into consideration, as follows. Patient demographic characteristics and comorbidities at discharge were determined from the hospital discharge databases at the index admission. Comorbidities included coexisting cardiovascular and lung diseases, chronic kidney or liver conditions, diabetes mellitus, dementia and malignant disease. Use of major cardiac medications at discharge was also recorded: $\beta$-blockers, angiotensin-converting-enzyme (ACE) inhibitors, antiplatelet drugs (ASA, clopidogrel), calcium-channel blockers, diuretics, warfarin and digoxin. Information was also obtained on any in-hospital procedure performed (catheterization, percutaneous coronary intervention, coronary artery bypass graft surgery), the year it was performed (according to the hospital's fiscal year), length of the hospital stay, the specialty of the treating physician (cardiologist, internist, other specialist, general practitioner), type of hospital (teaching or rural) and availability of a cardiac catheterization facility in the hospital. Finally, it was documented whether the patient was prescribed a statin within the I2 months before the AMI-related hospital admission.

Descriptive statistics were computed to compare baseline patient characteristics between the 2 study groups according to sex. Next, for both outcome end-points, hazard ratios associated with statin use were estimated in Cox regression models. In investigating the association between statins and the study outcomes, it was important to allow for the possibility of time-dependence (i.e., an accumulation of effect of statins over time), including time-dependent effects that are nonlinear. ${ }^{21}$ This was done by adding 3 product terms between the indicator of statin use and 3 follow-up periods after discharge ( $<$ I yr, I-3 yr and $>3$ yr) to the Cox models. The potential modifying effect of sex on the effectiveness of statin therapy was investigated by the addition of a product term between the indicator of statin use and the male/female indicator. In addition to the unadjusted Cox regression, multivariable Cox models were fitted that also adjusted for age, marital status, presence of comorbidities, use of cardiac medications at baseline (time zero), use of statins during the I2 months before the index hospital admission, the in-hospital procedure performed, the year the procedure took place, length of hospital stay, specialty of the treating physician and type of hospital.

Because information on the cause of death was unavailable for 223 patients, they were excluded from the primary analyses that used this outcome end-point. However, as part of sensitivity analyses in those analyses involving cardiac death as the outcome end-point, we assessed 2 alternative, "extreme" approaches to handling data for these 223 patients. In the first, all patients who died of unknown cause were assumed to have had cardiac causes, and were thus combined with known cardiac deaths for analysis. In the second, we assumed that all such deaths were noncardiac in origin, and combined them with known cases of noncardiac death. The study was approved by the Ethics Review Board of McGill University.

\section{Results}

Of 38543 patients who were discharged from hospital after AMI who were included in the analysis, 23815 (61.8\%) were men and $14728(38.2 \%)$, women. At the time of hospital discharge, I 4 7Io patients ( $38.2 \%$ ) were prescribed a statin. Both male and female non-users of statins tended to be slightly older than users (Table I). The 2 groups were comparable in terms of comorbid conditions except for congestive heart failure, which was more common among non-users than users of statins. In both sexes, statin users tended to have been prescribed other cardiac medications and undergone invasive cardiac procedures more frequently, compared with nonusers. The median length of stay in the hospital was similar in the 2 groups. Admissions by fiscal year are available in an online Appendix (www.cmaj.ca/cgi/content/full/176/3/333DCI).

Overall, statin users contributed a total of 28 88I personyears of follow-up to the analysis; statin non-users, 32792 person-years (Table 2). In the intervention group, $57 \%$ of patients in the user group continued to use statins throughout follow-up, whereas $38 \%$ of patients in the control group re- 
Table 1: Baseline characteristics of patients treated for an acute myocardial infarction, according to statin use and sex.

\begin{tabular}{|c|c|c|c|c|c|}
\hline \multirow[b]{3}{*}{ Characteristic } & \multicolumn{5}{|c|}{ No. (\%), unless otherwise specified } \\
\hline & \multicolumn{2}{|c|}{ Women } & \multicolumn{2}{|c|}{ Men } & \multirow[b]{2}{*}{$\begin{array}{c}\text { Total } \\
n=38543\end{array}$} \\
\hline & $\begin{array}{l}\text { Non-users } \\
n=9405\end{array}$ & $\begin{array}{c}\text { Users } \\
n=5323\end{array}$ & $\begin{array}{l}\text { Non-users } \\
n=14428\end{array}$ & $\begin{array}{c}\text { Users } \\
n=9387\end{array}$ & \\
\hline Age, mean (SD), y & $74.6(11.8)$ & $70.2(11.2)$ & $68.4(12.4)$ & $64.6(12.0)$ & $69.2(12.5)$ \\
\hline Married & $3762(40)$ & $2395(45)$ & $8801(61)$ & $5820(62)$ & $20813(54)$ \\
\hline \multicolumn{6}{|l|}{ Comorbidities } \\
\hline Cardiac dysrhythmia & $2069(22)$ & $958(18)$ & $3030(21)$ & $1690(18)$ & $7709(20)$ \\
\hline Cerebrovascular disease & 658 (7) & $319 \quad(6)$ & $866 \quad(6)$ & $469 \quad(5)$ & $2313 \quad(6)$ \\
\hline Congestive heart failure & $2663(28)$ & $1065(20)$ & $3030(21)$ & 1408 (15) & $8094(21)$ \\
\hline COPD & 1787 (19) & $852(16)$ & $3030(21)$ & $1408(15)$ & $6938(18)$ \\
\hline Dementia & 282 & 53 (1) & 144 (1) & 94 (1) & $771 \quad(2)$ \\
\hline Diabetes mellitus & $2633(28)$ & $1384(26)$ & $3463(24)$ & $1971(21)$ & $9636(25)$ \\
\hline Hypertension & 4608 (49) & 2608 (49) & $4473(31)$ & $3098(33)$ & $14646(38)$ \\
\hline Liver disease & $94 \quad(1)$ & $53 \quad(1)$ & 144 & $94 \quad(1)$ & 385 (1) \\
\hline Malignancy & 282 & $107 \quad(2)$ & $577 \quad(4)$ & $188 \quad(2)$ & 1156 \\
\hline Pulmonary edema & $188 \quad(2)$ & $53 \quad(1)$ & $144 \quad(1)$ & 94 (1) & 385 (1) \\
\hline Renal failure, acute & $470 \quad(5)$ & 213 & $721 \quad(5)$ & 282 & 1542 \\
\hline Renal failure, chronic & $1129(12)$ & $426 \quad(8)$ & $1731(12)$ & $751 \quad(8)$ & $3854(10)$ \\
\hline Shock & 94 (1) & $53 \quad(1)$ & 144 & 94 (1) & 385 (1) \\
\hline \multicolumn{6}{|l|}{ Admitting physician } \\
\hline General practitioner & 4420 (47) & $2182(41)$ & $6493(45)$ & $3943(42)$ & $16959(44)$ \\
\hline Cardiologist & $4044(43)$ & 2608 (49) & $6493(45)$ & $4506(48)$ & $17730(46)$ \\
\hline Internist & $1034(11)$ & $532(10)$ & $1443(10)$ & $939(10)$ & $3854(10)$ \\
\hline \multicolumn{6}{|l|}{ Medication use } \\
\hline ASA or clopidogrel & $4420(47)$ & $4418(83)$ & $6348(44)$ & $7979(85)$ & $23126(60)$ \\
\hline Beta-blockers & $4044(43)$ & $4046(76)$ & $5771(40)$ & 7416 (79) & $21199(55)$ \\
\hline ACE inhibitor & 1304 (33) & $3087(58)$ & $4328(30)$ & $5726(61)$ & $16188(42)$ \\
\hline Diuretics & $2445(26)$ & $1597(30)$ & $2453(17)$ & 1783 (19) & $8478(22)$ \\
\hline $\mathrm{Ca}^{++}$-channel blocker & 1599 (17) & $1118(21)$ & $1731(12)$ & $1314(14)$ & $5781(15)$ \\
\hline Warfarin & $940(10)$ & $692(13)$ & $1299 \quad(9)$ & $1314(14)$ & $4240(11)$ \\
\hline Digoxin & $564 \quad(6)$ & $266 \quad(5)$ & $721 \quad$ (5) & $375 \quad(4)$ & $1927 \quad(5)$ \\
\hline Nitrates, non-sublingual & $2445(26)$ & $1437(27)$ & 2741 (19) & 1784 (19) & $1272(22)$ \\
\hline $\begin{array}{l}\text { Used statins during } 12 \text { mo } \\
\text { before index admission }\end{array}$ & $2008(21)$ & $1811(34)$ & $3293(23)$ & $2507(27)$ & $38543(25)$ \\
\hline \multicolumn{6}{|l|}{ Procedure } \\
\hline Catheterization & 3198 (34) & $2928(55)$ & $6204(43)$ & $5632(60)$ & $18115(47)$ \\
\hline $\mathrm{PCl}$ & 1787 (19) & $1810(34)$ & $3607(25)$ & 3661 (39) & $10792(28)$ \\
\hline CABG & $376 \quad(4)$ & $373 \quad(7)$ & 1010 & $1032(11)$ & $2698 \quad(7)$ \\
\hline \multicolumn{6}{|l|}{ Type of hospital } \\
\hline Urban & 8928 (95) & $5074(95)$ & $13702(95)$ & $8916(95)$ & $36620(95)$ \\
\hline Rural & $476 \quad(5)$ & $249 \quad(5)$ & $726 \quad(5)$ & $471 \quad(5)$ & $1922 \quad(5)$ \\
\hline $\begin{array}{l}\text { Length of hospital stay, } \\
\text { median (IQR), d }\end{array}$ & $9(6-15)$ & $9(6-14)$ & $8(5-13)$ & $8(5-13)$ & $9(6-13)$ \\
\hline
\end{tabular}

$\mathrm{SD}=$ standard deviation, $\mathrm{COPD}=$ chronic obstructive pulmonary disease, $\mathrm{ACE}=$ angiotensin-converting enzyme, $\mathrm{ASA}=$ acetylsalicylic acid, $\mathrm{Ca}=$ calcium, $\mathrm{PCl}=$ percutaneous coronary intervention, $\mathrm{CABG}=$ coronary artery bypass graft surgery, $\mathrm{IQR}=$ interquartile range. 
mained non-users throughout the follow-up period. Similar percentages of male and female patients switched from the initial statin type (19\% and $18 \%$, respectively) or stopped statin use during the study follow-up ( $44 \%$ and $4 \mathrm{I} \%$, respectively). Among statin users, the mean atorvastatin-equivalent dose was similar between patients of either sex: men $19.5 \mathrm{mg}$, women $19.2 \mathrm{mg}$.

A total of 6172 patients died during the follow-up, 3053 from a cardiac cause (Table 3), with the overall unadjusted mortality rates being I0.4 all-cause events per Ioo personyears and and 5.0 cardiac events per Ioo person-years. In both men and women, statin users had lower overall unadjusted rates of both all-cause and cardiac death than did non-users.

The adjusted Cox regression models (Table 4) indicated that the statin-induced risk reduction for both all-cause and cardiac deaths increased with increased duration of treatment ( $p<0.00$ I for interaction between statin use and time since discharge, for both end-points). For all durations of followup, however, the magnitude of the reduction in risk was greater for men than for women $(p=0.04$ for interaction between statin use and sex for all-cause death; $p=0.06$, for cardiac death).

In the sensitivity analysis, when deaths from an unknown cause were assumed to have been of cardiac or noncardiac origin, the point estimates, confidence intervals and conclusions did not differ materially from those derived in the main analyses, which were based on an end-point of cardiac death.

\section{Interpretation}

In this study of 38543 post-AMI patients, we found a gradual accumulation over time of preventive effects from statin therapy that decreased overall and cardiac-related mortality rates in both sexes, with moderate risk reduction in the early followup period after discharge from hospital and considerable risk reduction after a longer duration of therapy. However, statin use conferred a lower degree of reduction in the risk of allcause and cardiac death to women than it did to men.
CVD-related preventive benefits of statins are thought to be mediated largely by LDL-cholesterol reduction, ${ }^{22-24}$ with ensuing decreased progression of atherosclerosis, regression of atherosclerotic lesions and slowed development of new lesions. Therefore, the design and analysis of studies attempting to quantify statin-conferred benefits should be lengthy enough to allow for the possibility of a lag between initiation of therapy and achievement of the maximum reduction in the occurrence of clinical events. ${ }^{21}$ Nonetheless, statin treatment has been associated with morbidity and mortality benefits early after AMI. ${ }^{25,26}$ These early benefits of statins could be mediated via both lipid-lowering and pleiotropic effects.

Several reasons are possible for the survival difference in male versus female patients. Differences in our study cannot be attributed to dose: in our study, men were prescribed virtually the same dose of statins as women (Table I). Some studies $^{27,28}$ have suggested that LDL- and total-cholesterol concentrations in serum may be stronger determinants in men of rates of CVD-related death than in women. A recent metaanalysis $^{21}$ of findings from studies of major coronary and major vascular events among patients with and without CHD, however, revealed that men and women exhibited similar reductions in event rates per unit of LDL-cholesterol reduction. In some animal studies, the rate of metabolism of simvastatin was found to be considerably higher in males than in females; ${ }^{29,30}$ the statin might therefore be expected to have a

Table 3: Incidence rates per 100 person-years for the study end-points, according to statin use by patients

\begin{tabular}{|c|c|c|c|c|c|}
\hline \multirow[b]{2}{*}{$\begin{array}{l}\text { End-point: } \\
\text { death }\end{array}$} & \multirow[b]{2}{*}{$\begin{array}{c}\text { Overall } \\
n=38543\end{array}$} & \multicolumn{2}{|c|}{ Women } & \multicolumn{2}{|c|}{ Men } \\
\hline & & $\begin{array}{c}\text { Non-users } \\
n=9405\end{array}$ & $\begin{array}{c}\text { Users } \\
n=5323\end{array}$ & $\begin{array}{l}\text { Non-users } \\
n=14428\end{array}$ & $\begin{array}{c}\text { Users } \\
n=9387\end{array}$ \\
\hline From any cause & 10.4 & 15.8 & 4.9 & 13.8 & 3.6 \\
\hline Cardiac-related & 5.0 & 8.5 & 2.9 & 6.7 & 1.8 \\
\hline
\end{tabular}

Table 2: Number $(\%)^{*}$ of patients who were or were not treated with statins, and their pattern of use

\begin{tabular}{|c|c|c|c|c|c|c|}
\hline Statin-related characteristic & \multicolumn{3}{|c|}{ Statin non-users } & \multicolumn{3}{|c|}{ Statin users } \\
\hline Use of statin within $1 \mathrm{yr}$ before index AMI & $2008(21)$ & $3293(23)$ & $5301(22)$ & $1811(34)$ & $2507(27)$ & $4318(29)$ \\
\hline \multicolumn{7}{|l|}{ Duration of follow-up } \\
\hline Median (interquartile range), $\mathrm{d}$ & $215(27-850)$ & $142(22-741)$ & $168(24-791)$ & $577(274-1057)$ & $577(279-1053)$ & $577(277-1055)$ \\
\hline \multicolumn{7}{|l|}{ Change in statin regimen } \\
\hline Discontinued initial use or non-use & $5256(56)$ & $9523(66)$ & $14779(62)$ & $2194(41)$ & $4147(44)$ & $6368(43)$ \\
\hline Switched during follow-up & 0 & 0 & 0 & $558(18)$ & 997 (19) & 1555 (19) \\
\hline Atorvastatin-equivalent dose, mean (SD), $\mathrm{mg} / \mathrm{d}$ & 0 & 0 & 0 & $19.2(12.0)$ & $19.5(12.1)$ & $19.4(12.1)$ \\
\hline Dosage, WHO DDD-equivalent, mean (SD) & 0 & 0 & 0 & $1.9 \quad(1.2)$ & $1.9(1.2)$ & $1.9(1.2)$ \\
\hline
\end{tabular}

$\mathrm{AMI}=$ acute myocardial infarction, $\mathrm{IQR}=$ interquartile range, $\mathrm{SD}=$ standard deviation, $\mathrm{WHO}=$ World Health Organization, $\mathrm{DDD}=$ defined daily dose *Unless specified otherwise. 
greater clinical effect on males. This hypothesis was nevertheless not corroborated in studies on human volunteers, which, in contrast, showed a lower degree of metabolism of simvastatin and lovastatin in men than in women. ${ }^{31}$ Moreover, several epidemiological studies ${ }^{11-13}$ have reported greater reductions in both LDL and total cholesterol in response to statins used by women than by men.

Another mechanism responsible for a differential effect of statins could be sex-dependent drug clearance, given that the clearance of lipid-soluble statins involves cytochrome $\mathrm{P} 450$ system enzymes (CYP) ${ }^{32-34}$ and that CYP expression can vary by sex. ${ }^{35}$ This could lead to between-sex differences in clearance rates, bioavailability and, consequently, the clinical effects obtained with the same dose of the drug. ${ }^{36}$

Our findings concur with those of earlier studies suggesting that statin therapy leads to a greater reduction in risk of cardiovascular events in men with CVD than in women with CVD. ${ }^{5,6}$ However, these previous studies generally included numbers of women that were insufficient to demonstrate the potential sex-treatment interaction or else did not account for the apparent time-dependence of statin-induced risk reductions.

Our study had several advantages. First, we were able to include a large number of patients of both sexes, which provided sufficient power to detect the sex-treatment interaction. Second, the patients included in our study represented a wider clinical and sociodemographic spectrum than those generally enrolled into randomized controlled trials, which should enhance the generalizability of our findings. Third, the patients had sufficiently long follow-up to allow us to demonstrate the added benefits of statin therapy with increased duration.

Some limitations of our study should also be considered. First, we had to rely on data obtained from an administrative database rather than on actual use of statin medications, which could introduce misclassification in statin-use status. However, such misclassification would likely be nondifferen- tial and tend to dilute the associations found. Second, because data on patients' serum lipid profile were unavailable, it was impossible for us to explore whether the apparent effect modification by sex was attributable to the differential effects of statins on LDL-cholesterol concentration or to pleiotropic effects. Third, data on cause of death were not available for all subjects. Still, our sensitivity analyses, where we considered 2 extreme-alternative scenarios with respect to cause of death, showed our findings to be robust. Next, although we adjusted for several codeterminants of all-cause and cardiac deaths, a possibility remains that residual confounding by indication could have introduced bias into our results. ${ }^{37}$ Nevertheless, since confounding by indication generally leads to dilution of the effect of the intervention studied, ${ }^{37}$ our estimates of the effects of statins are likely to be conservative. Even if the estimates of statins' effects are subject to some degree of residual confounding, it is unlikely that this would explain the differential effects of statins observed between men and women. Finally, because the database did not include such important patient characteristics as tobacco use and obesity status, we were unable to adjust for them; our findings of sex-differential effects of statins could therefore be at least partly attributable to potential differences in the levels of these factors.

Our findings could have potentially important implications for clinical practice. If corroborated by independent studies on the effects of statins on serum cholesterol levels, these results would suggest a possible need for reappraisal of target daily doses for statins: women might require a higher dose to achieve preventive effects similar to those observed in men. Moreover, the differential effect of statins in men and women could translate into differential outputs from costeffectiveness ${ }^{38}$ and risk-benefit analyses of statin therapy. ${ }^{39}$

Future studies should further investigate the apparent interaction between sex and the use of statin. Ultimately, the knowledge would better enable physicians and patients alike to make informed decisions on optimal treatment plans following an AMI.

Table 4: Crude and adjusted* hazard ratios, by sex, for the association between statin use and 2 end-points, for 3 selected durations of follow-up

Hazard ratio ( $95 \%$ confidence interval)

\begin{tabular}{|c|c|c|c|c|}
\hline \multirow{2}{*}{$\begin{array}{l}\text { End-point and } \\
\text { years of follow-up }\end{array}$} & \multicolumn{2}{|c|}{ Women } & \multicolumn{2}{|c|}{ Men } \\
\hline & Crude & Adjusted & Crude & Adjusted \\
\hline \multicolumn{5}{|c|}{ Death from any cause } \\
\hline$<1$ & $0.33(0.30-0.37)$ & $0.61(0.54-0.69)$ & $0.28(0.25-0.30)$ & $0.54(0.48-0.60)$ \\
\hline $1-3$ & $0.29(0.26-0.33)$ & $0.55(0.48-0.63)$ & $0.24(0.21-0.28)$ & $0.48(0.42-0.55)$ \\
\hline$>3$ & $0.22(0.17-0.27)$ & $0.38(0.31-0.49)$ & $0.18(0.16-0.20)$ & $0.34(0.30-0.39)$ \\
\hline \multicolumn{5}{|c|}{ Cardiac-related death } \\
\hline$<1$ & $0.37(0.32-0.43)$ & $0.70(0.60-0.81)$ & $0.30(0.26-0.34)$ & $0.59(0.51-0.69)$ \\
\hline $1-3$ & $0.29(0.24-0.35)$ & $0.56(0.46-0.68)$ & $0.23(0.19-0.28)$ & $0.47(0.39-0.58)$ \\
\hline$>3$ & $0.24(0.17-0.34)$ & $0.44(0.31-0.62)$ & $0.19(0.16-0.23)$ & $0.37(0.30-0.45)$ \\
\hline
\end{tabular}

*Adjusted for age, marital status, comorbidities, use of cardiac medications at baseline and use of statins in the year preceding the index hospitalization, in-hospital procedure performed, length of hospital stay, fiscal-calendar year, specialty of treating physician and type of hospital (teaching or rural). 
This article has been peer reviewed.

From the Divisions of Clinical Epidemiology (Karp, Chen, Pilote) and Internal Medicine (Pilote), McGill University Health Centre, Montréal, Que.

\section{Competing interests: None declared.}

Contributors: All coauthors have been involved in the conception, study design and analysis of data. They have all taken part in drafting and revising the manuscript, and have approved the final version for publication.

Acknowledgement: This study was undertaken as part of the Gender and Sex Determinants of Cardiovascular Disease (GENESIS) project, funded by the Canadian Institutes of Health Research (CIHR) Institutes of Gender and Health (IGH) and Circulatory and Respiratory Health (ICRH), and the Heart and Stroke Foundation of Canada. Louise Pilote is a research scholar of the CIHR and, at McGill University, a William Dawson Professor.

\section{REFERENCES}

I. Kerst LL, Mauro VF. Coronary event secondary prevention with statins irrespective of LDL-cholesterol. Ann Pharmacother 2004;38:1060-4.

2. Vrecer M, Turk S, Drinovec J, et al. Use of statins in primary and secondary prevention of coronary heart disease and ischemic stroke: meta-analysis of randomized trials. Int J Clin Pharmacol Ther 2003;41:567-77.

3. Wilt TJ, Bloomfield HE, MacDonald R, et al. Effectiveness of statin therapy in adults with coronary heart disease. Arch Intern Med 2004;164:I427-36.

4. Bandyopadhyay S, Bayer AJ, O'Mahony MS. Age and gender bias in statin trials. QJM 200I;94:I27-32.

5. Hague W, Forder P, Simes J, et al. Effect of pravastatin on cardiovascular events and mortality in $15 \mathrm{I} 6$ women with coronary heart disease: results from the LongTerm Intervention with Pravastatin in Ischemic Disease (LIPID) study. Am Heart 2003; I45:643-51

6. Shepherd J, Blauw GJ, Murphy MB, et al. Pravastatin in elderly individuals at risk of vascular disease (PROSPER): a randomized controlled trial. Lancet 2002;360:1623-30.

7. Lewis SJ, Sacks FM, Mitchell JS, et al. Effect of pravastatin on cardiovascular events in women after myocardial infarction: the Cholesterol And Recurrent Events (CARE) trial. J Am Coll Cardiol r998;32:I40-6.

8. Miettinen TA, Pyorala K, Olsson AG, et al. Cholesterol-lowering therapy in women and elderly patients with myocardial infarction or angina pectoris. Circulation I997;96:42II-8.

9. LaRosa JC, He J, Vupputuri S. Effect of statins on coronary disease: a meta-analysis of randomized controlled trials. JAMA 1999;282:2340-6.

IO. Cheung BMY, Lauder IJ, Lau CP, et al. Meta-analysis of large randomized controlled trials to evaluate the impact of statins on cardiovascular outcomes. Br JClin Pharmacol 2004;57:640-5I.

II. Clifton PM, Noakes M, Nestel PJ. Gender and diet interactions with simvastatin treatment. Atherosclerosis 1994;110:25-33.

I2. Jacobson TA, Jocubaitis LA, Amorosa LF. Fluvastatin and niacin in hypercholesterolemia: a preliminary report on gender differences in efficacy. Am J Med i994;96 (6A):64S-8S.

13. Nakajima K. Sex-related differences in response of plasma lipids to simvastatin the Saitama Postmenopausal Lipid Intervention Study. Clin Ther I999;21:2047-57.

I4. Herrington DM, Vittinghoff E, Lin F, et al. Statin therapy, cardiovascular events, and total mortality in the Heart and Estrogen/Progestin Replacement Study (HERS). Circulation 2002;105:2962-7.

I5. Hippisley-Cox J, Coupland C. The effects of statins on the mortality of patient with ischaemic heart disease: a population based cohort study with nested casecontrol analysis. Heart 2006;92:752-8

I6. Walsh JME. Pignone M. Drug treatment of hyperlimidemia in women. JAMA 2004; 29I:2243-52.
17. International classification of diseases, ninth revision, clinical modification (ICD g-CM). Washington: US Department of Health and Human Services; 1998.

I8. Kennedy CC, Brien SE, Tu JV. An overview of the methods and data in the CCORT Canadian Cardiovascular Atlas project. Can J Cardiol 2003;19:655-63.

I9. Zhou Z, Rahme E, Abrahamowicz M, et al. Effectiveness of statins for secondary prevention in elderly patients after acute myocardial infarction: an evaluation of class effect. CMAJ 2005;172:1187-94.

20. WHO Collaborating Centre for Drug Statistics Methodology. The Anatomical Therapeutic Chemical Classification System with Defined Daily Doses (ATC/DDD). Oslo: World Health Organization; 2003. Available: www.who.int/classifications latcddd/en (accessed 2006 Dec ig)

2I. Baigent C, Kearney PM, Blackwell L, et al. Efficacy and safety-lowering treatment: prospective meta-analysis of data from 90056 participants in I4 randomised trials of statins [published erratum in Lancet 2005;366:1358]. Lancet 2005;366:1267-78.

22. Robinson JG, Smith B, Maheshwari N, et al. Pleiotropic effects of statins: benefit beyond cholesterol reduction? A meta-regression analysis. J Am Coll Cardiol 2005; 46:1855-62.

23. Law MR, Wald NJ, Rudnicka AR. Quantifying effect of statins on low density lipoprotein cholesterol, ischaemic heart disease, and stroke: a systematic review and meta-analysis. $B M J$ 2003;326:1407-8.

24. Gould AL, Rossouw JE, Santanello NC, et al. Cholesterol reduction yields clinical benefit: impact of statin trials. Circulation 1998;97:946-52.

25. Fonarow GC. In-hospital initiation of statin therapy in acute coronary syndromes: maximizing the early and long-term benefits. Chest 2005;128:364I-5I.

26. Schwartz GG, Olsson AG, Ezekowitz MD, et al. Effects of atorvastatin on early recurrent ischemic events in acute coronary syndromes: the MIRACL study: a randomized controlled trial. JAMA 200I;285:I7II-8.

27. Bass KM, Newschaffer CJ, Klag MJ, et al. Plasma lipoprotein levels as predictors of cardiovascular death in women. Arch Intern Med I993;153:2209-I6.

28. Jacobs D, Blackburn H, Higgins M, et al. Report of the Conference on Low Blood Cholesterol: mortality considerations. Circulation 1992;86:1046-60.

29. Ohtawa M, Uchiyama N. Sex differences in metabolism of simvastatin by rat hepatic microsomes. Eur J Drug Metab Pharmacokinet 1992;17:175-8I.

30. Uchiyama N, Kagami Y, Saitoh Y, et al. Male-specific metabolism of simvastatin by rat liver microsomes. Chem Pharm Bull (Tokyo) 1991;39:236-8.

3I. Vree TB, Dammers E, Ulc I, et al. Differences between lovastatin and simvastatin hydrolysis in healthy male and female volunteers: gut hydrolysis of lovastatin is twice that of simvastatin. ScientificWorldJournal 2003;3:1332-43.

32. Vermes A, Vermes I. Genetic polymorphisms in cytochrome P450 enzymes: effect on efficacy and tolerability of HMG-CoA reductase inhibitors. Am J Cardiovasc Drugs 2004;4:247-55.

33. Lennernas H, Fager G. Pharmacodynamics and pharmacokinetics of the HMGCoA reductase inhibitors: similarities and differences. Clin Pharmacokinet 1997; 32:403-25.

34. Mauro VF. Clinical pharmacokinetics and practical applications of simvastatin. Clin Pharmacokinet 1993;24:195-202.

35. Wolbold $\mathrm{R}$, Klein $\mathrm{K}$, Burk $\mathrm{O}$, et al. Sex is a major determinant of $\mathrm{CYP}_{2} \mathrm{~A}_{4}$ expression in human liver. Hepatology 2003;38:978-88

36. Kivisto KT, Niemi M, Schaeffeler E, et al. Lipid-lowering response to statins is affected by CYP3A6 polymorphism. Pharmacogenetics 2004;i4:523-5.

37. Miettinen OS. The need for randomization in the study of intended effects. Stat Med ig83;2:267-7I.

38. Franco $\mathrm{OH}$, Peeters A, Looman CW, et al. Cost effectiveness of statins in coronary heart disease. J Epidemiol Community Health 2005;59:927-33.

39. Holden WL, Juhaeri J, Dai W. Benefit-risk analysis: a proposal using quantitative methods. Pharmacoepidemiol Drug Saf 2003;12:6II-6.

Correspondence to: Dr. Louise Pilote, Division of Internal Medicine, Royal Victoria Hospital, 687 Pine Ave. W, Rm. A4.2I, Montréal QC H3A IAI; fax 514 934-8293; louise.pilote@mcgill.ca 